\title{
Integración europea y cooperativismo: una reflexión sobre la sociedad cooperativa europea con motivo del año internacional del cooperativismo
}

\author{
Santiago Larrazabal Basañez \\ Profesor de Derecho Constitucional \\ Director del Departamento de Derecho Público \\ de la Facultad de Derecho de la Universidad de Deusto
}

Recibido: 12.07.2012

Aceptado: 10.09.2012

Sumario: I. Introducción. II. Valores y principios del cooperativismo e integración europea. III. La importancia de las cooperativas en la Unión Europea y para la integración europea. IV. Algunas consideraciones sobre los principios y la regulación de la sociedad cooperativa europea. V. La implantación y el fomento del cooperativismo y de la sociedad cooperativa europea en la Unión. VI. Conclusiones.

Resumen: El presente texto pretende concienciar de la importancia de la difusión del cooperativismo en el proceso de integración europea, también desde las instituciones de enseñanza y de cómo sus principios inspiradores deben penetrar más profundamente en el "acervo comunitario», en el marco de dicho proceso. Profundiza en los intentos que se han realizado para ello en el ámbito jurídico con el Reglamento (CE) n. ${ }^{\circ}$ 1435/2003 del Consejo, de 22 de julio de 2003, relativo al Estatuto de la sociedad cooperativa europea (SCE) y con la Directiva 2003/72/CE del Consejo, de la misma fecha, por la que se completa el Estatuto de la sociedad cooperativa europea en lo que respecta a la implicación de los trabajadores. Analiza las luces y las sombras de esta regulación y la implantación de la figura de la SCE desde su puesta en marcha en 2003 hasta hoy, y propone algunas medidas para revitalizarla, con el objetivo de «socializar» el modelo cooperativo en el proceso de integración social europea, sumido actualmente en una profunda crisis.

Palabras clave: integración europea, cooperativismo, sociedad cooperativa europea.

Abstract: This study aims to make us aware of the importance that the spread of cooperatives has had on European integration, also approached from educational institutions and how their inspiring principles should penetrate more deeply into the "acquis communautaire» in the framework of this process. It offers an in-depth study of the endeavours made to this effect in the legal scope through Commission Regulation EC no. 1435/2003 of 22 July 2003, on the bylaws of European Cooperative Society (SCE) and Commission 
Directive 2003/72/EC of the same date, which completes the bylaws on European cooperatives concerning implications for workers. The study analyses the positive and negative points of this regulation and the implementation of the SCE from the time it started in 2003 to the present. It also proposes some measures to revitalise it, with the purpose of "socialising» the cooperative model in the process of European social integration, which is currently undergoing a severe crisis. Society.

Key words: European integration, cooperativism, European Cooperative 


\section{Introducción}

En nuestras Facultades de Derecho y de Ciencias Económicas y Empresariales, tanto en los estudios de grado como en los de postgrado y de doctorado, suele darse siempre prioridad al estudio de las sociedades capitalistas, mientras que solo a veces se dedican esfuerzos y recursos al estudio de las sociedades cooperativas. Por eso no debe sorprendernos que los jóvenes juristas, economistas o graduados en Dirección y Administración de Empresas, no tengan en suficiente consideración la opción cooperativa, a pesar de que, en algunas ocasiones, ésta representa una vía tanto o más adecuada para un más satisfactorio desarrollo de sus actividades que la ofrecida por las sociedades capitalistas. Por ello, y escribiendo desde el País Vasco, uno de los territorios donde el cooperativismo ha arraigado con mayor fuerza y en el que tiene su sede el Grupo Mondragón, uno de los referentes del cooperativismo mundial, no debemos cansarnos de difundir con todos los medios a nuestro alcance el espíritu cooperativo y ofrecer toda la formación posible en relación con todos estos temas.

Estoy convencido de que debemos impulsar todo tipo de cursos universitarios específicos, tanto presenciales como a distancia y "on line», en grado, postgrado y Doctorado; diseñar asignaturas concretas, másteres, cursos, conferencias, jornadas, seminarios, promover grupos de investigación, tesis doctorales, monografías, etc. sobre el cooperativismo. Todo esfuerzo es poco para dar a conocer el modelo cooperativo, y no solo ya en el ámbito de la educación universitaria sino también en la enseñanza secundaria y en la formación profesional, por supuesto en todo el mundo, pero también en el ámbito al que se refiere este trabajo, es decir, el de la Unión Europea. Y así, deberíamos sumar esfuerzos con las instituciones europeas y, entre ellas, con la Comisión que, desde hace años, se comprometió a adoptar "las medidas necesarias para que los programas en materia de educación, formación, aprendizaje permanente y aprendizaje electrónico fomenten la participación de cooperativas, especialmente los programas de apoyo a proyectos y redes de especialistas transnacionales, y que sean útiles para desarrollar buenas prácticas en sectores innovadores». ${ }^{1}$

Por su parte, el Comité Económico Social Europeo propuso también en su día analizar la situación de la enseñanza cooperativa en los colegios y Universidades, animando a la Comisión a que apoyase la ela-

1 Comunicación de la Comisión al Consejo, al Parlamento Europeo, al Comité Económico y Social Europeo y al Comité de las Regiones sobre el fomento de las cooperativas en Europa, 23.2. 2004. COM (2004) 18 final, p. 8, acción 4. 
boración y difusión de material pedagógico específico, creando redes sobre las experiencias realizadas, incluyendo la dimensión cooperativa en los planes de enseñanza y fomentando el espíritu empresarial cooperativo, pues el desconocimiento de este tipo de empresa es un obstáculo importante para el desarrollo de las sociedades cooperativas en Europa². Y a su vez, el Comité de las Regiones puso también de manifiesto la importancia de la participación de las propias cooperativas en los programas de educación, formación, aprendizaje electrónico y aprendizaje permanente, así como la labor de estímulo a las Universidades y a los centros de enseñanza secundaria para organizar programas de formación para dirigentes de cooperativas ${ }^{3}$. Parafraseando lo dicho por el padre del cooperativismo vasco, el Padre José María de Arizmendiarrieta, se trataría de "socializar el conocimiento cooperativo».

No solo desde la Unión Europea sino desde otras instituciones de ámbito mundial, se ha querido destacar el importante papel que el cooperativismo ha desarrollado, desarrolla y puede desarrollar en el progreso de nuestro mundo en general y de la integración europea en particular. No por casualidad, el año 2012 ha sido declarado por la Organización de las Naciones Unidas, Año Internacional del Cooperativismo. Y consecuentemente, la Asociación Internacional de Derecho Cooperativo quiere celebrar tal declaración dedicando a esta efemérides su línea de Investigación correspondiente al presente ejercicio. También otras instituciones se han querido sumar a esta labor de difusión del cooperativismo. Y así, desde la Universidad de Deusto, a la que pertenezco como profesor e investigador, en el marco de su Instituto de Estudios Cooperativos de la Facultad de Derecho, a través de su Anuario; desde la propia Asociación Internacional de Derecho Cooperativo, a través de su Boletín, y también desde la Academia Vasca de Derecho, a través de su correspondiente Boletín, hemos querido hacernos eco una vez más de esta labor de difusión del cooperativismo. En mi caso, como miembro del Equipo de Investigación en «Integración Europea» de la Universidad de Deusto, de la Asociación Internacional de Derecho Cooperativo y de la Academia Vasca de Derecho, me

2 Dictamen del Comité Económico y Social Europeo sobre la Comunicación de la Comisión al Consejo, al Parlamento Europeo, al Comité Económico y Social Europeo y al Comité de las Regiones sobre fomento de las cooperativas en Europa, 415. Pleno (9-10 de marzo de 2005), Diario Oficial (en adelante, DO) 2005/C 234/01, de 22 de septiembre, epígrafes 5.3.2. y 6.2 .

3 Dictamen del Comité de las Regiones sobre la Comunicación de la Comisión al Consejo, al Parlamento Europeo, al Comité Económico y Social Europeo y al Comité de las Regiones sobre fomento de las cooperativas en Europa», 55. ${ }^{\circ}$ Pleno, 16-17 de junio de 2004, DO 2004/17, de 22 de diciembre, epígrafe 1.6. ISSN: 1134 - 993X, Núm. 46/2012, Bilbao, págs. 161-183 
sumo, modestamente, a esa labor, con la reflexión que presento a continuación ${ }^{4}$.

Y es que, precisamente, considero que el cooperativismo y la integración europea pueden colaborar en un proceso simbiótico con beneficios mutuos: el cooperativismo y sus principios pueden ser de gran utilidad en el proceso de integración europea y la integración europea puede ser también un marco idóneo para fomentar el cooperativismo no solo en el interior de los Estados miembros de la Unión (cooperativismo nacional) sino también entre los Estados miembros de la Unión Europea (cooperativismo transnacional). Precisamente, en este marco, he querido dedicar esta reflexión a una institución ya conocida pero quizá no todo lo que debiera y que podría incluso ser considerada como una de las primeras «herramientas transnacionales de la economía social europea»: me refiero a la "sociedad cooperativa europea».

Por todo ello, creo que merece una atención especial, atención que, tanto la Asociación Internacional de Derecho Cooperativo como la Academia Vasca de Derecho ${ }^{5}$, ya le prestaron en el momento de ponerse en marcha, pero que, transcurridos ya unos años desde su puesta en funcionamiento, deberíamos volver a retomar, en el marco de este Año Internacional de las Cooperativas 2012 y aprovechando que la propia Comisión Europea ha hecho público en febrero de este año el primer Informe sobre la aplicación del Reglamento CE n. ${ }^{\circ}$ 1435/2003 del Consejo, de 22 de julio de 2003, relativo al Estatuto de la sociedad cooperativa europea ${ }^{6}$.

Precisamente a ello dedicaré las siguientes páginas de este artículo, no tanto desde un análisis exhaustivo de su regulación jurídica concreta, sino más bien desde los principios que la inspiran, principios que

4 Llegado a estas líneas, quiero agradecer especialmente los valiosos consejos que para la realización de este artículo me han dado dos ilustres estudiosos del cooperativismo, queridos colegas de la Universidad de Deusto y buenos amigos: los profesores Javier Divar Garteiz-Aurrecoa y Alejandro Martínez Charterina.

5 Véase por ejemplo el artículo que publicó en su momento el actual Presidente de la Asociación Internacional de Derecho Cooperativo, el ya mencionado profesor Javier Divar, sobre «Funcionamiento orgánico de la Sociedad Cooperativa Europea, SCE», en el Boletín de la Asociación Internacional de Derecho Cooperativo, n. ${ }^{\circ} 38$ (2004), pp. 1522, o la Jornada monográfica que la Academia Vasca de Derecho dedicó en 2006 a «La implantación del Estatuto de la Sociedad cooperativa europea», Boletín de la Academia Vasca de Derecho, año IV, número extraordinario II, junio de 2006.

6 Informe de la Comisión al Parlamento Europeo, al Consejo, al Comité Económico y Social Europeo y al Comité de las Regiones sobre la aplicación del Reglamento (CE) n. ${ }^{\circ}$ 1435/2003 del Consejo, de 22 de julio de 2003, relativo al Estatuto de la sociedad cooperativa europea (SCE), fechado en Bruselas el 23 de febrero de 2012, COM (2012) 72 final. 
emanan de lo más hondo del movimiento cooperativo y que conectan directamente con los fundamentos mismos que deben sostener el proceso de integración europea. Comencemos, pues, hablando de principios cooperativos y de integración europea.

\section{Valores y principios del cooperativismo e integración europea}

Como es bien conocido, las primeras cooperativas, asociaciones y mutualidades surgieron a finales del siglo XVIII y en lo que concierne a Europa se desarrollaron a lo largo del siglo xIx en varios países como Inglaterra, Italia, Francia o España. Hoy en día, la Sociedad Cooperativa ha sido definida por la Alianza Cooperativa Internacional (ACI) como «una asociación autónoma de personas reunidas voluntariamente para satisfacer sus aspiraciones y necesidades económicas, sociales y culturales comunes por medio de una empresa cuya propiedad es colectiva y en la que el poder se ejerce democráticamente» ${ }^{7}$. Su identidad se refuerza con valores cooperativos como la democracia, la igualdad, la equidad, la solidaridad, la transparencia o la responsabilidad social y con principios como la adhesión voluntaria, el poder democrático ejercido por sus miembros, la participación económica de estos o el compromiso hacia la colectividad.

Sus principios particulares giran en torno al principio de primacía de la persona, con la regla "una persona un voto» como símbolo. Y además, todos estos valores y principios cooperativos adoptados por la Alianza Cooperativa Internacional $(\mathrm{ACl})$ en 1995, han sido recogidos también por las Naciones Unidas ${ }^{8}$ y por la Organización Internacional del Trabajo ${ }^{9}$, que incluye también los siguientes principios: la adhesión voluntaria y abierta, la gestión democrática y la participación económica de los socios, la autonomía e independencia de la cooperativa, el derecho de los socios a la educación, formación e información, el deber de cooperación entre cooperativas o el interés por la comunidad. Y no hay que olvidar además, que al haber sido aprobada por los Estados miembros de la Unión Europea, esta Recomendación de la OIT repre-

7 Carta cooperativa adoptada en 1995 en el Congreso de la Alianza Cooperativa Internacional $(\mathrm{ACl})$, de Manchester.

8 Resolución 56/114, adoptada en la 88. ${ }^{a}$ reunión plenaria de la Asamblea General de las Naciones Unidas, el 19 de diciembre de 2001 (A/RES/56/114) y el Informe 2001/68, del Secretario General de las Naciones Unidas, de 14 de mayo de 2001.

9 Recomendación 193 sobre la promoción de las cooperativas, adoptada en la 90. ${ }^{a}$ reunión de la Conferencia Internacional del Trabajo, el 20 de junio de 2002. 
senta el «primer consenso europeo sobre las normas y el fomento de las cooperativas».

Por todo ello, las cooperativas, en particular, y la economía social, en general, han ido adquiriendo cada vez más importancia en el ámbito de la Unión Europea y eso explica que, como se dice en el Preámbulo de la reciente Ley española de Economía Social de $2011^{10}$, se presentasen en su día tres Propuestas de Reglamento de Estatutos de la Asociación Europea, de la Cooperativa Europea y de la Mutualidad Europea, de las cuales solo llegó a buen término la Sociedad Cooperativa Europea ${ }^{11}$.

Por su parte, la Carta de principios de la Economía Social de 2002, de la Conferencia Europea de Cooperativas, Mutualidades, Asociaciones y Fundaciones, antecesora de la actual Asociación Europea de Economía Social, ha logrado introducir en el "acervo comunitario» principios tales como la primacía de la persona y del objeto social sobre el capital, la adhesión voluntaria y abierta, el control democrático de sus integrantes, la conjunción de intereses de los usuarios y del interés general, la defensa del principio de solidaridad y responsabilidad, la autonomía de gestión y independencia de los poderes públicos y el destino de los excedentes a la consecución de objetivos en favor del desarrollo sostenible, del interés de los servicios a sus integrantes y del interés social. Todo ello ha tenido reflejo en el Informe sobre Economía social del Parlamento Europeo de 26 de enero de $2009^{12}$ o en distintos Dictámenes del Consejo Económico y Social del año 2000 (Economía Social y Mercado Único) ${ }^{13}$ y de 2009 (Distintos Tipos de Empresas) $)^{14}$.

Precisamente, la reciente Ley española de Economía Social de $2011^{15}$ recoge, de forma muy destacada estos principios. Su artículo $2 .{ }^{\circ}$

10 Ley 5/2011, de 29 de marzo, de Economía Social (BOE n. ${ }^{\circ} 76$, de 30 de marzo).

11 Los otros dos proyectos, el de la Asociación Europea y el de Mutualidad Europea, fueron retirados por la Comisión en 2006, al resultar infructuosas las negociaciones con el Consejo. El objetivo final de las tres propuestas era la creación de una forma jurídica europea propia, fomentar las empresas de economía social y garantizar la igualdad de estas a la hora de competir con las sociedades capitalistas.

12 Informe del Parlamento Europeo sobre Economía Social 2008/2250 INI. Ponente: Patrizia Toia.

13 CES 242/2000, de 3 de marzo de 2000.

14 2009/C 318/05, de 1 de octubre de 2009.

15 Sobre esta novedosa Ley, pueden consultarse, por ejemplo: Alfonso Sánchez, Rosalía y EMBID IRUjo, José Miguel. Economía social y economía sostenible, Ed. Aranzadi, Cizur Menor, 2011; FajARdo García, Isabel Gemma. «El fomento de la Economía Social en la legislación española», REVESCO: Revista de Estudios Cooperativos, n. ${ }^{\circ}$ 107(2012), pp. 58-97; Padilla Ruiz, Pedro. «Comentarios a la Ley 5/2011, de Economía Social», 
define la economía social como el conjunto de las actividades económicas y empresariales que en el ámbito privado llevan a cabo entidades que persiguen o bien el interés colectivo de sus integrantes, o bien el interés general económico o bien ambos. $Y$ en su artículo 4 . $^{\circ}$ recoge los principios orientadores de la actuación de las entidades de economía social:

a) Primacía de las personas y del fin social sobre el capital, que se concreta en la gestión autónoma, transparente, democrática y participativa, lo que lleva a priorizar la toma de decisiones más en función de las personas y de sus aportaciones de trabajo y servicios prestados a la entidad o en función del fin social, que en relación a sus aportaciones al capital social.

b) Aplicación de los resultados obtenidos en la actividad económica principalmente en función del trabajo aportado y del servicio o actividad realizada por los socios o por sus miembros, y en su caso, al fin social objeto de la entidad.

c) Promoción de la solidaridad interna y con la sociedad que favorezca el compromiso con el desarrollo local, la igualdad de oportunidades entre hombres y mujeres, la cohesión social, la inserción de personas en riesgo de exclusión social, la generación de empleo estable y de calidad, la conciliación de la vida personal, familiar y laboral y la sostenibilidad.

d) Independencia respecto de los poderes públicos.

Finalmente, el artículo $8 .^{\circ}$ de la Ley, se ocupa del fomento y difusión de la economía social y establece que los poderes públicos tendrán como objetivos de sus políticas de promoción de economía social, entre otros:

a) Remover o eliminar los obstáculos que impidan el inicio y el desarrollo de una actividad económica de las entidades de economía social, prestándose especial atención a la simplificación

Revista Aranzadi Doctrinal, n. ${ }^{\circ} 3$ (2011), pp. 129-137; Paniagua Zurera, Manuel. Las empresas de la economía social. Más allá del comentario a la Ley 5/2011, de economía social, Marcial Pons, Madrid, 2011; PAz Canalejo, Narciso. Comentario sistemático a la Ley 5/2011, de Economía Social, Tirant lo Blanch, Valencia, 2012; Pedreño Frutos, Juan Antonio. "La Ley de Economía Social: un reconocimiento jurídico e institucional a la Economía Social Española», Noticias de la Economía pública social y cooperativa, n. 54 (2010), pp. 59-62; Pedreño Frutos, Juan Antonio. "La Ley española de economía social, un referente», Consejeros: la revista del buen gobierno y la responsabilidad corporativa, n. ${ }^{\circ} 68$ (enero de 2012), pp. 44-45; VV.AA. Informe para la elaboración de una ley de fomento de la economía social, Ministerio de Trabajo y Asuntos Sociales, Madrid, 2010. ISSN: 1134 - 993X, Núm. 46/2012, Bilbao, págs. 161-183 
de los trámites administrativos para la creación de entidades de economía social.

b) Facilitar las diversas iniciativas de economía social.

c) Promover los principios y valores de la economía social.

d) Promocionar la formación y readaptación profesional en el ámbito de las entidades de economía social.

e) Facilitar el acceso a los procesos de innovación tecnológica y organizativa a los emprendedores de las entidades de economía social.

f) Crear un entorno que fomente el desarrollo de las iniciativas económicas y sociales en el marco de la economía social.

g) Involucrar a las entidades de la economía social en las políticas activas de empleo, especialmente en favor de los sectores más afectados por el desempleo, las mujeres, los jóvenes y los parados de larga duración.

h) Introducir referencias a la economía social en los planes de estudio de las diferentes etapas educativas.

i) Fomentar el desarrollo de la economía social en áreas como el desarrollo rural, la dependencia y la integración social.

Y dentro de las entidades que integran la economía social, volviendo al tema específico de las cooperativas, y en defensa de los principios cooperativos, las Naciones Unidas, en la Resolución que acaba de ser mencionada, instaron a todos los Estados a asegurar un entorno propicio en el que las cooperativas puedan participar en igualdad de condiciones con otras formas de empresa. Y en esta misma línea, en el marco de la integración europea, las cooperativas, manteniendo sus principios esenciales, los que conforman su ADN constitutivo, deben poder competir en igualdad con otras fórmulas empresariales que responden a principios totalmente distintos, pues, como dijo la Comisión Europea, no necesitan un trato de favor sino una normativa que «... las sitúe en un plano de igualdad, en el sentido de que les permita actuar sin restricciones ni obligaciones basadas en objetivos de política nacional a las que no están sujetas otras fórmulas empresariales con las que las cooperativas compiten en las economías modernas de mercado» ${ }^{16}$.

16 Comunicación de la Comisión sobre fomento de las cooperativas en Europa (2004), op. cit., número 3.2.4. 


\section{La importancia de las cooperativas en la Unión Europea y para la integración europea}

Ya en 1998, la Alianza Cooperativa Internacional confirmaba que en Europa, nada menos que 140 millones de personas eran miembros de sociedades cooperativas y estas daban empleo a 2,3 millones de personas ${ }^{17}$. Las cooperativas tienen una especial vinculación con las comunidades locales, en las que están especialmente arraigadas, son básicas para mantener la cohesión social, permiten la participación más completa en el desarrollo económico y social de toda la población y juegan un papel muy importante en territorios menos desarrollados o con importantes necesidades de reconversión. Pero al mismo tiempo, son capaces de desarrollar sus actividades más allá de sus países de origen, en el ámbito de la Unión Europea y más allá de las fronteras de la Unión, incluso a través de grupos formados por empresas cooperativas, lo que les permite afrontar los retos de la globalización y resultar competitivas.

Pero además, tienen un gran «potencial» para desarrollar la cooperación entre las pequeñas y medianas empresas y mejorar su posición en el mercado y para prestar servicios de calidad a los clientes que son miembros de la cooperativa, en ámbitos básicos para la cohesión social como son la sanidad, la educación, la protección social y la asistencia social ${ }^{18}$. De hecho, el modelo cooperativo no solo es eficaz para avanzar en la integración económica europea sino también en su integración social. Como ha puesto de manifiesto la Comisión, el modelo cooperativo ha resultado muy eficaz para integrar objetivos sociales y en algunos países miembros se han adoptado fórmulas jurídicas cooperativas específicas para facilitar estas actividades $^{19}$.

17 Statistics and information on European co-operatives, Alianza Cooperativa Internacional, Ginebra, 1998 (htpp:/www.ica.coop/Europe).

18 Cfr. Dictamen del Comité Económico y Social Europeo sobre la «Comunicación de la Comisión... (2005), op. cit., apartados 1.7, 1.8 y 4.4., 5.1.2, y Dictamen del Comité de las Regiones sobre la Comunicación de la Comisión..., op. cit., 1.2 y 1.3.

19 Pensemos, por ejemplo, en la Ley italiana n. ${ }^{\circ} 381$, de 1991, mediante la que se crearon en Italia un gran número de cooperativas, las denominadas «cooperativas de integración» que daban empleo a un importante número de personas desfavorecidas y que acogieron a personas con graves riesgos de exclusión social; en modelo francés de "sociedad cooperativa de interés colectivo», introducida en 2001, o en la "Community Interest Company» del Reino Unido, o en las cooperativas de discapacitados, que se han puesto en marcha en otros países de la Unión Europea (cfr. Comunicación de la Comisión sobre fomento de las cooperativas en Europa (2004), op. cit., número 2.3.2. 
Asimismo, tienen una posición destacada en ámbitos como la banca, los seguros, la distribución alimentaria, la farmacia y la agricultura y permiten desarrollar cada vez mejor relevantes objetivos de la Unión Europea en materia de mejora del empleo, de integración social, de desarrollo regional y rural, reactivación económica de las regiones europeas alejadas y con escasez de capitales, etc. Entre los países de la Unión que pertenecen a Europa Occidental, las cooperativas tienen una larga tradición y un gran prestigio y si bien es cierto que en algunos países miembros de la Unión pertenecientes a la Europa Central que formaron parte en su día al bloque soviético y tuvieron economías planificadas, eran la forma de empresa más libre autorizada por los regímenes de planificación centralizada y desde entonces y en ocasiones «... padecen el estigma de estar identificadas con aquellos... es importante recordar al respecto que las cooperativas pueden contribuir al desarrollo equilibrado de las economías y sociedades de los nuevos Estados miembros y países candidatos» ${ }^{20}$.

En la actualidad, y en el ámbito de la Unión Europea, existen unas 250.000 empresas cooperativas, de las que son socios 163 millones de ciudadanos (es decir, casi uno de cada tres ciudadanos de la Unión) y que emplean a 5,4 millones de personas ${ }^{21}$. Precisamente por la importancia de las cooperativas en la Unión Europea, esta procedió por fin a dar un paso adelante en el ámbito de la integración europea en materia cooperativa y aprobó dos importantes normas en relación con la denominada sociedad cooperativa europea (SCE, de su nombre en latín «Societas Cooperativa Europaea»): el Reglamento (CE) n. ${ }^{\circ}$ 1435/2003 del Consejo, de 22 de julio de 2003, relativo al Estatuto de la sociedad cooperativa europea (SCE) y la Directiva 2003/72/CE del Consejo, de la misma fecha, por la que se completa el Estatuto de la sociedad cooperativa europea en lo que respecta a la implicación de los trabajadores, normas de las que me ocuparé a continuación.

20 Comunicación de la Comisión sobre fomento de las cooperativas en Europa (2004), op. cit., número 2.1.2.

21 Por dar algunos datos bien significativos, las cooperativas europeas tienen importantes cuotas de mercado en el ámbito de la agricultura (83\% en los Países Bajos, 79\% en Finlandia, 55\% en Italia, 50\% en Francia); sector forestal (60\% en Suecia, $31 \%$ en Finlandia), banca (50\% en Francia, 37\% en Chipre, 35\% en Finlandia, 31\% en Austria, $21 \%$ en Alemania), cooperativas de consumo (36\% de cuota de mercado en Finlandia, $20 \%$ en Suecia), farmacéutica y del área sanitaria (21\% en España, 18\% en Bélgica), etc. Y en Italia, las cooperativas representan casi el $15 \%$ del total de la economía. 


\section{Algunas consideraciones sobre los principios y la regulación de la sociedad cooperativa europea.}

No es mi intención desarrollar en este artículo un estudio exhaustivo de la regulación jurídica concreta de la Sociedad Cooperativa Europea, que ha sido abordado por autores mucho más versados que yo en derecho cooperativo22, sino más bien situar esta figura en el

22 En nuestra doctrina jurídica pueden consultarse, por ejemplo: Alfonso SÁnCHEZ, Rosalía. «El desarrollo normativo de la sociedad cooperativa europea: propuestas de implantación, Boletín de la Academia Vasca de Derecho, año 4, n. 2 (junio de 2006), número extraordinario y monográfico, dedicado a la «Implantación del Estatuto de la Sociedad cooperativa europea, pp. 11-52; Alfonso SÁnchez, Rosalía. "¿Regulación supranacional del grupo cooperativo paritario?: la sociedad cooperativa europea», Anuario de la Fundación Ciudad de Lleida, n. 17 (2006), pp. 19-23; Alfonso SÁncheZ, Rosalía. "La Sociedad cooperativa europea. Un nuevo tipo social en un escenario complejo», Noticias de la Unión Europea, n. 252 (2006), pp. 19-34; Alfonso SÁnchez, Rosalía. La Sociedad cooperativa europea domiciliada en España, Ed. Aranzadi, Cizur Menor, 2008; Alfonso SánCHez, Rosalía. "Respuesta del ordenamiento jurídico español ante la realidad de la Sociedad cooperativa europea», CIRIEC-España. Revista jurídica de economía social y cooperativa, n. ${ }^{\circ} 21$ (2010), pp. 169-198; BARAHONA RIBER, A. «El Estatuto de la sociedad cooperativa europea», en ARgudo PERIz, José Luis (coord.). El cooperativismo y la economía social en la sociedad del conocimiento: 1963-2003. Cuarenta años de formación en cooperativismo y economía social en Aragón, Prensas Universitarias de Zaragoza, pp. 565-568; BorJABAd BelLido, Ramón. «La Sociedad cooperativa europea», Anuario de la Fundación Ciudad de Lleida, n. 21 (2010), pp. 181-196; CoBo DEL Rosal, Manuel. "Principales aspectos del nuevo régimen jurídico de la sociedad cooperativa europea (Reglamento núm. 1435/2003, del Consejo Europeo, de 22 de julio de 2003)», Revista de Derecho de Sociedades, 21 (2003), pp. 484-496; DABORMIDA, Renato. "El estatuto de la sociedad cooperativa europea», CIRIEC-España, Revista de economía pública, social y cooperativa, n. ${ }^{\circ} 13,2003$, pp. 29-50; Divar GARTEIz-AurRreCoA, Javier. "Funcionamiento orgánico de la Sociedad cooperativa europea, SCE», Boletín de la Asociación Internacional de Derecho Cooperativo, n. ${ }^{\circ} 38$ (2004), pp. 15-22; FrancH F20111-2012), pp. 435-441; LuXA, Juan. «El nuevo régimen de la Sociedad cooperativa europea tras la aprobación de la Ley 3/2011, de 4 de marzo», Revista de Derecho de Sociedades, n. 37 (González Fernández, María Belén / Benavides Velasco, Patricia. «La sociedad cooperativa europea: análisis del Reglamento 1435/2003, por la que se regula su estatuto jurídico», Revista de Derecho de Sociedades, n. 27 (2006), pp. 273-297; loAKIMIDIS, Apostolos. "Sociedad cooperativa europea: problemática de implantación en los Estados miembros», en Boletín de la Academia Vasca de Derecho, año 4, n. ${ }^{\circ}$ 2, extraordinario y monográfico, dedicado a la «Implantación del Estatuto de la Sociedad cooperativa europea»), pp. 53-66; LAMBEA RUEDA, Ana. "Aspectos jurídicos interesantes del Reglamento 1435/2003, de 22 de julio, sobre el Estatuto de la Sociedad cooperativa europea», en González Porras, José Manuel y Méndez González, Fernando P. (coords.). Libro homenaje al profesor Manuel Albaladejo García, Editum, Ediciones de la Universidad de Murcia, 2004, vol. 2, pp. 2597-2618; LAMBEA RuedA, Ana. "La Sociedad cooperativa europea: el Reglamento 1435/2003, de 22 de julio», Revista de Derecho Privado, 88-3 (2004), pp. 300-323; LAMBEA RuEDA, Ana. "Criterios orientativos para optar a la calificación de sociedad cooperativa europea», REVESCO. Revista de Estudios Cooperati- 
marco general del proceso de la integración europea y del cooperativismo como objetivo a fomentar en el seno de dicho proceso. $Y$ en este proceso, hay que detenerse necesariamente en el Reglamento (CE) n. ${ }^{\circ}$ 1435/2003 del Consejo, de 22 de julio de 2003, relativo al Estatuto de la sociedad cooperativa europea (SCE) ${ }^{23}$.

El proceso para la aprobación del Reglamento no fue fácil y siempre fue a remolque de la promulgación del Reglamento relativo a la Sociedad Anónima Europea24. Además, fue objeto de un recurso de anulación ante el Tribunal de Justicia por parte del Parlamento Europeo que impugnaba no su contenido sino la base jurídica del antiguo Tratado CE en el que se fundamentaba, pues entendía que esta debía ser el antiguo artículo 95 CE (relativo a la aproximación de las legislación de los Estados miembros) y no aquella en la que se fundamenta el Re-

vos, n. ${ }^{\circ} 87$ (2005), pp. 77-105; LAMBEA RuedA, Ana. «Marco jurídico de la Sociedad cooperativa europea domiciliada en España», CIRIEC-España, Revista jurídica de economía social y cooperativa, n. ${ }^{\circ} 17$ (2006), pp. 85-112; MARTínez SegoviA, Francisco José. «Directiva y Reglamento sobre la Sociedad cooperativa europea: Introducción», Revista de Derecho de Sociedades, n. 21 (2003), pp. 347-376; MARTínez SegoviA, Francisco José. "Primera aproximación al Estatuto de la Sociedad cooperativa europea», REVESCO, Revista de estudios cooperativos, n. ${ }^{\circ} 80$ (2003), pp. 61-106; Minondo SANz, Francisco Javier. "El nuevo Estatuto de la Sociedad cooperativa europea», en CIRIEC-España, Revista de economía pública, social y cooperativa, n. ${ }^{\circ} 41$ (2002), pp. 9-24; Morán García, Manuel Eduardo. "Completado el estatuto jurídico de la Sociedad cooperativa europea domiciliado en España», en Esplugues-Mota, Carlos / Palao Moreno, Guillermo / Penadés Fons, Manuel Alejandro (coords.). Nuevas fronteras del derecho de la Unión Europea: liber amicorum José Luis Iglesias Buhigues, Tirant lo Blanch, Valencia, 2012, pp. 761778; NAMORADO, Rui y FAJARDO GARCíA, Isabel Gemma. "La sociedad cooperativa y la integración empresarial», en NAMORADO, Rui / CHAVES ÁVILA, Rafael / FAJARDO GARCía, Isabel Gemma (coords.). Integración empresarial cooperativa: posibilidades, ventajas e inconvenientes (ponencias del II Coloquio Ibérico de Cooperativismo y Economía Social), ClRIEC, Madrid, 2004, pp. 203-224; PANIAgua Zurera, Manuel. «El Estatuto de la Sociedad cooperativa europea: el problema de su aplicación en España», La Sociedad Cooperativa, n. 34 (2007), pp. 19-23; PASTOR SEMPERE, Carmen. "La sociedad cooperativa europea domiciliada en España», REVESCO, Revista de Estudios Cooperativos, n. 97 (2009), pp. 117-144; Rodríguez AbelendA, Pablo. "La Sociedad cooperativa europea y su adecuación a los principios de la ACl», CIRIEC-España, Revista jurídica de economía social y cooperativa, n. ${ }^{\circ} 15$ (2004), pp. 129-170; VICENT CHULIÁ, Francisco. "La Sociedad cooperativa europea», CIRIEC-España, Revista jurídica de economía social y cooperativa, n. ${ }^{\circ} 14$ (2003), pp. 51-82; ZenNA, Franco Antonio. «La Sociedad cooperativa europea, una ocasión perdida para la armonización y creación de un Derecho Comunitario Unitario: los problemas de implantación del Estatuto en España», Anales de Derecho, n. ${ }^{\circ} 26$ (2008), pp. 649-666.

23 DO L 207, de 18 de agosto de 2003, p. 1.

24 Reglamento (CE) n. ${ }^{\circ}$ 2157/2001 del Consejo, de 8 de octubre de 2001, por el que se aprueba el Estatuto de la Sociedad Anónima Europea (SE), DO L 294, de 10 de noviembre de 2001, p. 1 
glamento, es decir, el antiguo artículo 308 CE (que era la base jurídica a la que se podía recurrir cuando ninguna otra disposición del Tratado confería a las instituciones comunitarias la competencia necesaria para adoptarlo).

El Tribunal de Justicia, en su Sentencia de 2 de mayo de $2006^{25}$, hizo una afirmación importante en este sentido, pues entendió que el Reglamento, que deja intactas las distintas normativas nacionales existentes en materia de cooperativas, no tiene por objeto aproximar las legislaciones de los Estados miembros aplicables a las sociedades cooperativas, sino "crear una nueva forma de sociedad cooperativa que se superpone a las nacionales». Y el hecho de que no fije de manera exhaustiva el conjunto de normas aplicables a las sociedades cooperativas europeas y remita, en algunos extremos, al Derecho del Estado miembro en cuyo territorio tenga su domicilio social la Sociedad Cooperativa Europea, no desvirtúa la afirmación anterior, pues esa remisión tiene carácter subsidiario. Por todo ello, el Tribunal rechazó el recurso de anulación y confirmó que el fundamento jurídico del Reglamento era correcto, es decir, el antiguo artículo 308 CE y no el antiguo artículo 95 CE ${ }^{26}$.

Las Disposiciones Generales relativas a la SCE se recogen en el capítulo I del Reglamento. Por ofrecer algunas breves pinceladas respecto de las mismas, diré que el Reglamento establece en su artículo $1 .^{\circ}$ que podrán constituirse sociedades cooperativas en el territorio de la Comunidad Económica Europea (hoy Unión Europea) en la forma de una Sociedad Cooperativa Europea (SCE) en las condiciones y modalidades establecidas en el propio Reglamento. Muy brevemente, diremos que sus características principales son las siguientes: el capital suscrito estará dividido en participaciones, el número de socios y el capital serán variables, cada socio responderá hasta el límite del capital que haya suscrito, salvo que los estatutos de la Sociedad dispongan otra cosa; la Sociedad tendrá por objeto principal la satisfacción de las necesidades y el fomento de las actividades económicas y sociales de sus socios, en particular mediante la conclusión de acuerdos con ellos para el suministro de bienes o servicios o la ejecución de obras en el desempeño de la actividad que ejerza o haga ejercer la Sociedad.

25 Sentencia del Tribunal de Justicia (Gran Sala) de 2 de mayo de 2006, Parlamento Europeo contra Consejo de la Unión Europea, C-436/03, Rec. p. I-03733, apartados 4346.

26 Sobre esta Sentencia, vid. ORdóñez Solís, David. «La adopción del Derecho de Sociedades y el equilibrio de los poderes legislativos en la Unión Europea: el Estatuto de la Sociedad cooperativa europea (Comentario de la STJCE de 2 de mayo de 2006, C-436/03)», Noticias de la Unión Europea, n. 273 (2007), pp. 31-38. 
También podrá tener por objeto la satisfacción de las necesidades de sus socios mediante el fomento de su participación en actividades económicas, en una o más sociedades cooperativas europeas o en sociedades cooperativas nacionales y podrá llevar a cabo sus actividades a través de una filial. No podrá admitir que terceros no socios se beneficien de sus actividades o participen en sus operaciones (salvo disposición en contrario de sus Estatutos) y tendrá personalidad jurídica.

Como se dice en el párrafo $13 .^{\circ}$ del Preámbulo del Reglamento, el objetivo era permitir la constitución de SCE por particulares residentes en distintos Estados miembros o por entidades jurídicas sujetas a las legislaciones de Estados miembros distintos, o incluso la constitución de SCE mediante la fusión de dos cooperativas existentes o por la transformación de una cooperativa nacional en SCE sin mediar disolución, siempre que dicha cooperativa tenga su domicilio social y su administración central en un Estado miembro y un establecimiento o filial en otro. Por eso, el artículo $2 .^{\circ}$ del Reglamento afirma que la SCE podrá constituirse por:

- Un mínimo de cinco personas físicas que residan al menos en dos Estados miembros.

- Un mínimo de cinco personas físicas y sociedades, así como otras entidades jurídicas de Derecho público o privado constituidas con arreglo al ordenamiento jurídico de un Estado miembro que residan o estén reguladas por el ordenamiento de al menos dos Estados miembros.

- Por sociedades y otras entidades jurídicas de Derecho público o privado constituidas con arreglo al ordenamiento jurídico de un Estado miembro, reguladas por el ordenamiento jurídico de al menos dos Estados miembros.

- Por fusión de cooperativas constituidas con arreglo al ordenamiento jurídico de un Estado miembro y con domicilio social y administración central en la Comunidad, si al menos dos de ellas están reguladas por el ordenamiento jurídico de distintos Estados miembros.

- Por transformación de una sociedad cooperativa constituida con arreglo al ordenamiento jurídico de un Estado miembro y con domicilio social y administración central en la Comunidad, siempre que haya tenido un establecimiento o una filial regulada por el ordenamiento jurídico de otro Estado miembro durante, al menos, dos años.

Finalmente, también prevé que los Estados miembros podrán disponer que una entidad jurídica que no tenga su administración central 
en la Comunidad pueda participar en la constitución de una SCE, siempre y cuando tal entidad jurídica esté constituida con arreglo al ordenamiento jurídico de un Estado miembro, tenga su domicilio social en ese mismo Estado miembro y tenga una vinculación efectiva y continua con la economía de un Estado miembro.

Los artículos $3 .^{\circ}$ y $4 .^{\circ}$ del Reglamento se ocupan del capital de la SCE: el capital suscrito no podrá ser inferior a 30.000 euros, si bien la legislación de un Estado miembro podrá fijar un capital suscrito superior para entidades que ejerzan determinados tipos de actividad, legislación que se aplicará a las SCE domiciliadas en dicho Estado miembro. El capital social podrá aumentarse o reducirse y ello no requerirá la modificación de los estatutos. El capital suscrito estará representado por las participaciones de los socios expresadas en moneda nacional y los estatutos podrán prever que las distintas categorías de participaciones confieran distintos derechos de en lo que respecta a la distribución de resultados y el capital sólo podrá constituirse con activos susceptibles de valoración económica y deberán ser nominativas. Los Estatutos de la SCE se regulan en el artículo $3 .^{\circ}$ del Reglamento.

Volviendo al análisis de los principios inspiradores de la Sociedad Anónima Cooperativa, el párrafo $100^{\circ}$ del Preámbulo del Reglamento establece que el objetivo de la SCE debe ser la satisfacción de las necesidades de sus socios o el desarrollo de sus actividades económicas o sociales, respetando, entre otros, los principios siguientes:

a) Sus actividades han de tener por objeto el beneficio mutuo de los socios.

b) Sus socios han de ser además, clientes, trabajadores o proveedores o estar implicados de alguna forma en las actividades de la SCE.

c) El control debe estar repartido equitativamente entre los socios, aunque puede admitirse la ponderación de votos para reflejar la aportación de cada socio a la SCE.

d) La remuneración del capital tomado en préstamo y de las participaciones debe ser limitada.

e) Los beneficios han de distribuirse en función de las actividades realizadas con la SCE o utilizarse para satisfacer las necesidades de los socios.

f) No deben existir obstáculos artificiales a la adhesión.

g) El activo neto y las reservas se adjudicarán, en caso de disolución, con arreglo al principio de adjudicación desinteresada, es decir, a otra entidad cooperativa que persiga objetivos similares o fines de interés general. 
Aunque como cualquier Reglamento de la Unión Europea es directamente aplicable sin necesidad de ninguna adaptación en todos los países de la Unión, el legislador español dictó la Ley 3/2011, de 4 de marzo, por la que se regula la Sociedad Cooperativa Europea con domicilio en España 27 , ya que el Reglamento Europeo remite en varios aspectos al desarrollo de los Estados miembros en lo relativo a la legislación aplicable para garantizar la aplicación efectiva de dicho Reglamento (artículo 78). En el caso español, y dada la competencia del Estado en materia de legislación mercantil (artículo 149.1.6 de la Constitución), el Estado Central regula a través de esta Ley promulgada, casi 8 años después de la entrada en vigor del Reglamento comunitario, lo relativo a la regulación, inscripción y publicación de actos, traslado, oposición fusión, transformación y disolución de la SCE con domicilio en España, siempre sin perjuicio de las competencias de las Comunidades Autónomas españolas en materia de cooperativas.

Junto al Reglamento de la SCE, y en la misma fecha, se dictó la Directiva 2003/72/CE del Consejo, de 22 de julio de 2003, por la que se completa el Estatuto de la sociedad cooperativa europea en lo que respecta a la implicación de los trabajadores ${ }^{28}$, que sigue también el modelo de la Directiva 2001/86/CE del Consejo de 8 de octubre de 2001 por la que se completa el Estatuto de la sociedad anónima europea en lo que respecta a la implicación de los trabajadores ${ }^{29}$. El propósito principal de la Directiva es garantizar los derechos de los trabajadores en lo que respecta a su implicación en las decisiones que puedan afectarles ${ }^{30}$. La Directiva 2003/72/CE fue objeto de transposición al sistema jurídico español, junto con la Directiva 2001/86/CE a través de la Ley 31/2006, de 18 de octubre, sobre implicación de los trabajadores en las Sociedades Anónimas y Cooperativas Europeas ${ }^{31}$.

27 BOE n. ${ }^{\circ} 57$, de 8 de marzo de 2011.

28 DO L 207, de 18 de agosto de 2003, p. 25.

29 DO L 294, de de 10 de noviembre de 2001, p. 22.

30 Sobre este tema, pueden consultarse: Aguilar González, María Cristina. «La aplicación en España de las normas comunitarias sobre la participación de los trabajadores en la sociedad anónima europea y en la sociedad cooperativa europea», Justicia Laboral: Revista de Derecho del Trabajo y de la Seguridad Social, n. 32 (2007), pp. 89-120; Monereo Pérez, José luis y Fernández Avilés, J.A. La participación de los trabajadores en las Sociedades Anónimas y Cooperativas Europeas. Estudio sistemático y crítico de la Ley 31/2006, de 18 de octubre, Ed. Aranzadi, Pamplona, 2007; Pérez CAMPos, Ana y CANo GalÁn, Yolanda. La implicación de los trabajadores en las Sociedades Anónimas y Cooperativas Europeas, Civitas, Madrid, 2007; VAldés DAL-Re, Fernando. "Los derechos de implicación de los trabajadores en la Sociedad cooperativa europea», Relaciones Laborales: Revista crítica de teoría y práctica, n. ${ }^{\circ} 2$ (2007), pp. 43-54.

31 BOE n. ${ }^{\circ} 250$, de 19 de octubre de 2006. 
Pero, como veremos posteriormente, pronto se comprobó que desde la entrada en vigor del Reglamento se habían constituido pocas sociedades cooperativas europeas y, además, con pocos trabajadores. Desde el punto de vista técnico-jurídico, la falta de éxito de la SCE se achacó, no sin cierta razón, a la complejidad de las disposiciones reguladoras de su Estatuto. Sin embargo, también hay que decir que dicha regulación introduce notables elementos positivos: el capital mínimo, la obligatoriedad de que el domicilio social esté situado en el mismo Estado miembro que su administración central, la clarificación en cuanto a la ley aplicable (la ley del domicilio social), la posibilidad de que, además de la asamblea general, exista o bien un órgano de administración (sistema monista) o bien un órgano de control y un órgano de dirección (sistema dual); el refuerzo de la seguridad jurídica al establecerse la obligación de registrar toda SCE en el Estado miembro de su domicilio social, en el registro que señale la legislación de ese Estado miembro de conformidad con la legislación aplicable a las sociedades anónimas, etc.

En relación con la Directiva, los expertos indicaron que su transposición había tenido un impacto positivo en el Derecho del Trabajo y en la legislación de cooperativas, que había servido de incentivo para el trabajo y las actividades conjuntas entre los sindicatos y las organizaciones representativas de las cooperativas tanto a nivel nacional como europeo. Pero la Comisión también identificó algunos problemas concretos en su aplicación como, por ejemplo, en lo relativo al procedimiento de negociación transnacional, al uso indebido de los procedimientos previstos en ella y a los problemas transversales comunes a las diferentes Directivas sobre implicación de los trabajadores ${ }^{32}$.

\section{La implantación y el fomento del cooperativismo y de la sociedad cooperativa europea en la Unión.}

Ciertamente, desde el punto de vista del desarrollo del cooperativismo en la Unión Europea, hay algunas cuestiones que deberían ser mejoradas, por ejemplo, en relación con la libertad de establecimiento, ya que en algunos países está prohibido desarrollar en régimen de coo-

32 Informe de 16 de septiembre de 2010 de la Comisión al Consejo, al Parlamento Europeo, al Comité Económico y Social Europeo y al Comité de las Regiones sobre la revisión de la Directiva 2003/72/CE del Consejo, de 22 de julio de 2003, por la que se completa el Estatuto de la Sociedad cooperativa europea en lo que respecta a la implicación de los trabajadores. COM (2010) 481 final, 4.3. y 4.4. 
perativas algunas actividades (cosa que el Reglamento de la Sociedad Cooperativa Europea mantiene en su art. 8.2), lo que choca con la libertad de establecimiento, uno de los pilares básicos de la Unión. También es mejorable el tratamiento fiscal de las cooperativas, de tal manera que los Estados miembros concedan incentivos fiscales a las cooperativas según su utilidad social o su contribución al desarrollo regional siempre bajo el control del respeto a los principios y valores cooperativos, es decir, el principio democrático y la solidaridad, así como la asunción directa de las funciones empresariales por parte de los socios, bien sean trabajadores o consumidores. Y podrían también fomentarse los grupos formados por empresas cooperativas, pues favorecen las estrategias de asociación y cooperación entre empresas cooperativas, lo que les permitiría afrontar mejor los retos de la mundialización y de la competitividad, desarrollar marcas comunes o gamas de bienes y servicios, manteniendo y reforzando su identidad cooperativa ${ }^{33}$.

En cuanto a la implantación real de la Sociedad Cooperativa Europea, hasta ahora la apuesta más clara por un modelo de cooperativismo transnacional en la Unión Europea, la Comisión ha dado a conocer su Informe al respecto en febrero de este mismo año ${ }^{34}$ y sus conclusiones son un tanto decepcionantes. Veamos por qué: el principal objetivo de la SCE es facilitar las actividades transfronterizas y transnacionales de las cooperativas, pero como la SCE es un instrumento facultativo, de tal manera que las cooperativas en sus actividades $u$ operaciones transfronterizas pueden elegir o bien adoptar la forma jurídica de una SCE o de una cooperativa nacional, la gran mayoría de cooperativas han optado claramente por la regulación cooperativa nacional y no por la transnacional.

El objetivo, muy loable además, era, como acabamos de ver, superar los obstáculos que las disparidades legislativas en materia de cooperativas de los distintos países miembros de la Unión Europea suponían para las actividades comerciales transfronterizas de las cooperativas, permitiendo a las cooperativas reestructurarse a través de fusiones transfronterizas, trasladar su domicilio social a un Estado miembro dis-

33 Dictamen del Comité Económico y Social sobre la Comunicación de 2004 de la Comisión sobre fomento de cooperativas en Europa..., op. cit., 4.2.2., 4.2 .3 y 4.4, y Dictamen del Comité de Regiones sobre la misma Comunicación, op. cit., 2.1.3.

34 Informe de 23 de febrero de 2012 de la Comisión al Parlamento Europeo, al Consejo, al Comité Económico y Social Europeo y al Comité de las Regiones, sobre la aplicación del Reglamento (CE) n. ${ }^{\circ}$ 1435/2003 del Consejo, de 22 de julio de 2003, relativo al Estatuto de la sociedad cooperativa europea (SCE), COM (2012) 72 final. En particular, los apartados 3, 4, 5 y 6 . 
tinto de aquel en el que se establecieron en un principio y adoptar el sistema de gestión corporativa que más les interesase.

Sin embargo, los resultados no han sido muy brillantes: en noviembre de 2011, fecha de las últimas estadísticas disponibles sobre el número de SCE constituidas (en los veintisiete Estados miembros de la Unión Europea y en tres Estados pertenecientes al Espacio Económico Europeo - Islandia, Liechtenstein y Noruega-), había 24 sociedades cooperativas europeas ${ }^{35}$.

Tal y como se recoge en el informe de la Comisión, entre las razones para constituir una sociedad cooperativa nacional o una sociedad cooperativa europea y acerca de dónde hacerlo, el elemento más importante a tener en cuenta ha sido el de la fiscalidad (imposición sobre los ingresos de las cooperativas, imposición sobre los beneficios o excedentes de los socios, imposición de reservas irrepartibles, impuesto de sociedades, etc.). Como la fiscalidad directa no es competencia de la Unión ni, por tanto, el Estatuto de la SCE regula la fiscalidad, que es competencia de los Estados miembros, el tratamiento fiscal sigue variando de un país a otro y el hecho de que se trate de una SCE no añade nada específico en este aspecto. Otros elementos a tener en cuenta a la hora de constituir una cooperativa en tal o cual país son los requisitos del Derecho nacional en materia de trabajo, la complejidad y rigidez de la legislación nacional sobre cooperativas y la existencia de buenas redes de comunicaciones y de un entorno administrativo favorable para las empresas.

Tampoco la SCE ha supuesto hasta ahora grandes ventajas a la hora de realizar cambios estructurales transfronterizos en una agrupación, y solo las grandes cooperativas financieras y las mutuas de seguros podrían estar interesadas en la fórmula de la SCE, que podría re-

35 En España, por ejemplo, solo hay constituida una, por cierto, directamente vinculada con la enseñanza y la cultura vascas. De hecho, han sido las «ikastolas» vascas, es decir, las escuelas de enseñanza integral en lengua vasca («euskera»), las que han formado la «Euskal Herriko Ikastolak SCE» («lkastolas de Euskal Herria, Sociedad Cooperativa Europea), constituida en 2009 por 12 personas jurídicas, según lo previsto en el artículo 2.1.c) del Reglamento y domiciliada en el Parque Tecnológico de Zamudio, en Bizkaia. Esta SCE agrupa a «ikastolas» de la Comunidad Autónoma Vasca y de la Comunidad Foral de Navarra, en el Estado español (de las que prácticamente todas son cooperativas) y a «ikastolas» del País Vasco francés o Iparralde, en el Estado francés, (que no son cooperativas). Sobre este asunto, puede consultarse: Cooperatives Europe / Euricse / Ekai Center, Study on the implementation of the Regulation 1435/2003 on the Statute for European Cooperative Society (SCE): Final Study, Executive Summary and Part I: Synthesis and comparative report 5 October 2010, p. 308. Este informe puede consultarse en: http://ec.europa.eu/enterprise/policies/sme/files/sce_final_study_part_i. pdf (última consulta, 10 de julio de 2012). ISSN: 1134 - 993X, Núm. 46/2012, Bilbao, págs. 161-183 
sultarles útil para la reorganización y simplificación de su estructura de grupo, pero en la práctica, no se ha creado ninguna SCE de este tipo. En cuanto a la posibilidad de trasladar el domicilio social a otro Estado miembro, no se ha considerado por las cooperativas una ventaja de la SCE respecto de las cooperativas nacionales, ni tampoco se ha visto demasiado interés en crear una SCE para realizar fusiones transfronterizas. De hecho, la ventaja más importante para constituir una SCE ha sido más bien de imagen, pues puede ayudar a las cooperativas que se deciden por adoptar esa fórmula a penetrar en mercados en los que la marca europea es más fácil de comercializar que la nacional, como ocurre, por ejemplo, en la prestación de servicios sociales.

A esto hay que añadir, dice el Informe, la falta de conocimiento de la SCE por las empresas, los costes de creación y la complejidad del procedimiento a seguir. Además, por un lado, una gran parte de las cooperativas son pequeñas empresas que operan en el interior de un país y conocen mejor su legislación nacional, que suele ser más sencilla y flexible que la regulación de la Unión Europea, por lo que no le ven a la fórmula de la SCE una especial ventaja. Y por otro lado, y en el caso de las grandes agrupaciones cooperativas que pretenden operar a nivel europeo, ninguna de ellas ha recurrido a la SCE hasta ahora.

Como posibles medidas a adoptar para revitalizar la SCE, y tras haber recabado informes de expertos y realizado una consulta pública al respecto, la Comisión ya adelantó en su Comunicación sobre la iniciativa en favor del emprendimiento social, de 25 de octubre de 201136, que habría que simplificar el Reglamento de la SCE, para reforzar su autonomía con respecto de las legislaciones nacionales y abordar su modificación en el marco de una reflexión más amplia sobre el futuro del Derecho de Sociedades de la Unión Europea. Pronto veremos si hay o no verdadero interés en hacerlo y hacer de la SCE un instrumento más atractivo para el cooperativismo europeo.

\section{Conclusiones}

Primera. Resulta necesario hacer un mayor esfuerzo en todo lo relativo a la difusión del cooperativismo en la Unión Europea, especialmente en la enseñanza secundaria, en la formación profesional y en la Universidad, fomentando también el espíritu empresarial cooperativo,

36 Comunicación de la Comisión sobre la iniciativa en favor del emprendimiento social, de 25 de octubre de 2011, COM (2011) 682. 
con la participación de las propias cooperativas en los programas de formación en materia cooperativa.

Segunda. Los valores y principios cooperativos y de la economía social son perfectamente compatibles con los propios de una Unión Europea más social y deben introducirse aún más en el denominado «acervo comunitario», haciendo que las instituciones de la Unión no solo los asuman teóricamente, sino estableciendo también una normativa mucho más ambiciosa que permita a las cooperativas y a las demás instituciones de economía social competir en plano de igualdad con otras fórmulas empresariales en una economía de mercado cada vez más globalizada.

Tercera. En la actualidad, y en el ámbito de la Unión Europea, existen unas 250.000 empresas cooperativas, de las que son socios 163 millones de ciudadanos (es decir, prácticamente uno de cada tres ciudadanos de la Unión), que emplean a 5,4 millones de personas. Precisamente por la importancia de las cooperativas en el ámbito de la Unión Europea, esta se decidió por fin a dar un paso adelante en el ámbito de la integración europea en materia cooperativa y aprobó dos importantes normas en relación con la denominada sociedad cooperativa europea: el Reglamento (CE) n. ${ }^{\circ}$ 1435/2003 del Consejo, de 22 de julio de 2003, relativo al Estatuto de la sociedad cooperativa europea (SCE) y la Directiva 2003/72/CE del Consejo, de la misma fecha, por la que se completa el Estatuto de la sociedad cooperativa europea en lo que respecta a la implicación de los trabajadores. Su objetivo era permitir la constitución de sociedades cooperativas europeas por particulares residentes en distintos Estados miembros o por entidades jurídicas sujetas a las legislaciones de Estados miembros distintos, o incluso mediante la fusión de dos cooperativas existentes o por la transformación de una cooperativa nacional en SCE sin mediar disolución siempre que dicha cooperativa tenga su domicilio social y su administración central en un Estado miembro y un establecimiento o filial en otro.

Cuarta. Desde el punto de vista técnico-jurídico, el Reglamento de la SCE cuenta en su «haber» con indudables elementos clarificadores, entre otros: el del capital mínimo, la obligatoriedad de que el domicilio social esté situado en el mismo Estado miembro que su administración central, la clarificación en cuanto a la ley aplicable (la ley del domicilio social), la posibilidad de que exista un sistema monista o dual de organización y el refuerzo de la seguridad jurídica al establecerse la obligación de registrar toda SCE en el Estado miembro de su domicilio social en el registro que señale la legislación de ese Estado miembro de conformidad con la legislación aplicable a las sociedades anónimas. Sin embargo, también hay que apuntar en su «debe» su complejidad jurídica y la necesidad de su simplificación. 
Quinta. Es cierto que desde 2003, fecha de la aprobación del Reglamento, se han constituido pocas sociedades cooperativas europeas (había únicamente 24 a finales de 2011), lo que, como acabamos de ver, se ha achacado a la complejidad de las disposiciones reguladoras del Estatuto de la SCE. Sin embargo, también es cierto que, aunque el objetivo del Reglamento era facilitar las actividades transfronterizas y transnacionales de las cooperativas, al ser la SCE un instrumento facultativo, de tal manera que las cooperativas podían adoptar la fórmula jurídica o bien de una SCE o bien de una cooperativa nacional, la gran mayoría de las cooperativas han optado por la fórmula que les era más próxima y conocida, es decir, la cooperativa nacional. Además, no han encontrado ninguna ventaja fiscal en optar por una SCE y las constantes remisiones a la legislación nacional por parte de la SCE han hecho que se acuda directamente a constituir cooperativas nacionales en vez de cooperativas transnacionales. Tampoco la SCE ha supuesto hasta ahora grandes ventajas a la hora de realizar cambios estructurales transfronterizos en una agrupación y si a esto unimos la falta de conocimiento de la SCE por las empresas y el hecho de que la mayoría de las cooperativas son empresas pequeñas que operan en un solo país y que conocen mejor su legislación nacional, podremos explicar el discreto éxito que ha tenido la SCE hasta ahora.

Sexta. Para revitalizar la SCE se han apuntado varias medidas: básicamente, difundir mucho más su conocimiento, simplificar el Reglamento de la SCE y reforzar su autonomía con respecto a las legislaciones nacionales, abordando su modificación en el marco de una reflexión más amplia sobre el futuro del Derecho de sociedades de la Unión Europea. En todo caso, no conviene desanimarse a las primeras de cambio porque los instrumentos transnacionales dentro de la Unión Europea requieren tiempo para madurar y la SCE no es una excepción. Quienes creemos que el proceso de integración europea es imparable a pesar de sus vaivenes, confiamos en que los valores del cooperativismo y de la economía social vayan abriéndose paso cada vez más en la Unión Europea, para que esta no sea solo una Unión Económica y Monetaria sino Social y, algún día, también Política. En este sentido, estoy convencido de que el cooperativismo y sus instrumentos jurídicos transnacionales, como la SCE, pueden jugar en el futuro un papel relevante en el proceso. Parafraseando de nuevo al P. Arizmendiarreta, "socialicemos» el modelo cooperativo para ayudar a hacer de esta Europa en crisis económica y de identidad, una Europa más social, si queremos una integración no solo económico-financiera, sino una integración europea completa, más justa y solidaria para todos. 